\title{
INVESTIGAR 0 NO INVESTIGAR. \\ PAUTAS PARA ELABORAR UNA TESIS DE DERECHO
}

\author{
Milushka Rojas UlLoA* \\ Universidad de Lima, Lima, Perú \\ mrojasu@ulima.edu.pe
}

Recibido: 14/11/2020 Aprobado: 21/11/2020

doi: https://doi.org/10.26439/iusetpraxis2021.n052.4959

\begin{abstract}
RESUMEN. Nuestro derecho ha sido en gran medida el resultado de un cúmulo de aportes del derecho extranjero; por tanto, es el momento de darle a la investigación en derecho el sitial que le corresponde dentro del ordenamiento jurídico nacional. Por ello, abordaremos qué es la investigación jurídica, cómo se inicia la investigación, cuáles son las pautas para encontrar el problema por investigar y cómo se determina la estructura de la tesis a partir del desarrollo de lineamientos generales para elaborarla. De este modo, se llega a comprender la importancia del aporte del investigador al desarrollo del derecho nacional.
\end{abstract}

Si bien este artículo pretende que los graduados consigan el objetivo final y no se queden solo en el intento, consideramos que el presente aporte es el primero de cara a algunas preguntas que se nos presentan cuando pensamos en hacer investigación.

PALABRAS CLAVE: investigación jurídica / tesis de derecho / derecho comparado / ideas para investigar

\footnotetext{
* Doctora en Derecho y Ciencia Política por la Universidad Nacional Mayor de San Marcos. Magíster en Derecho Civil y Comercial por la Universidad de San Martín de Porres. Abogada por la Universidad de Lima e investigadora por el IDIC. Docente de pregrado y posgrado en diversas universidades peruanas.
} 


\section{TO RESEARCH OR NOT TO RESEARCH. GUIDELINES FOR PREPARING A LAW THESIS}

ABSTRACT. Our law has been mostly the result of a wealth of contributions from foreign law; therefore, it is time to give legal research its rightful place within the national legal system. To that end, we will address what legal research is, how this research begins, what are the guidelines to find the problem to be researched, and how to determine the structure of the thesis from the general guidelines for thesis preparation. Thus, the importance of researchers' contribution to the development of national law is understood. Although this article intends graduates to achieve the final objective and not to remain only in the attempt, we consider that this contribution is the first in the face of some questions that arise when we think about doing research.

KEYWORDS: legal research / law thesis / comparative law / ideas for researching 


\section{INTRODUCCIÓN}

A lo largo de los veinte años en que vengo impartiendo la docencia universitaria, sea en pregrado o posgrado, he aprendido más de lo que he podido transmitir a mis alumnos porque todos son diferentes: algunos son más participativos; otros, más alegres; algunos, más callados, y están también aquellos que cuestionan todo. Pero no cabe duda de que he podido descubrir con cada uno de ellos todo un mundo por explorar y muchas ideas por investigar. Esas ideas llevan a preguntarse por la razón de ser de las diversas instituciones y el impacto que producen en la sociedad, todo ello con el fin de medir la eficacia y pertinencia en el derecho interno de cada país.

Entonces, nos preguntamos ¿cómo podemos contribuir al desarrollo del derecho? La respuesta es una: investigando, indagando, analizando los problemas que se originan conforme aplicamos el derecho en la actividad profesional, ya sea como jueces, abogados litigantes, docentes, políticos, funcionarios, entre otros. Sabemos lo invalorable que es la experiencia que se adquiere en el quehacer diario, en la asistencia a congresos nacionales e internacionales; durante una entrevista, una lectura, una clase y, en general, gracias a cualquier evento en el que participemos y que dé origen a preguntas cuyas respuestas son poco precisas, insatisfactorias o inexistentes. Investigar es indagar, hurgar dentro de lo desconocido, buscar la respuesta a un fenómeno jurídico. En definitiva, es encontrar la verdad frente al problema para el que, en ese momento, no hallamos respuesta alguna (Constantinesco y Da Costa,1981).

Mediante el presente aporte queremos transmitir algunas ideas prácticas sobre cómo elaborar nuestra tesis de derecho para que refleje el interés que motivó la elección del tema por desarrollar. Por ello, conoceremos lo que es la investigación jurídica y empezaremos con el planteamiento del problema para llegar a determinar la estructura de la tesis. Asimismo, es importante tener claros los lineamientos generales para elaborarla, su normativa, para poder comprender la importancia del aporte del investigador al desarrollo del derecho nacional.

\section{DISCUSIÓN DEL PROBLEMA}

Como sabemos, muchos de los ordenamientos jurídicos en el mundo han sido receptores de otros, y confirmamos que el derecho peruano también. Esto lo podemos comprobar en la historia del derecho peruano, desde la conquista, cuando los españoles impusieron a la población indígena sus normas, además de sus costumbres (Basadre, 1984). Fue un derecho incorporado, impuesto al derecho ya existente en la comunidad que fue vencida: la voluntad del pueblo quedó subyugada a la voluntad de la Corona española, representada por el virrey (Basadre, 1937). 
Con la independencia del país el 28 de julio de 1821, proclamada por el libertador don José de San Martín, llegó también la emancipación frente al derecho impuesto por los colonizadores. La primera norma fue eliminar el tributo a la Corona española, tan injusto y criticado por los emancipadores (Basadre, 1984). A partir de ese período, se vio la necesidad de crear un derecho que fuera de la mano con los ideales de la nueva nación, puesto que todo derecho refleja el sentir del pueblo en el momento y lugar donde se pretende aplicar. Fue entonces, en 1823, cuando se dio la primera Constitución peruana. Contenía los principios generales que inspirarían y guiarían a la nueva República del Perú (Basadre, 1937). Más adelante, se encargó la elaboración de los primeros códigos al entonces primer presidente de la corte suprema, Manuel Lorenzo de Vidaurre y Encalada (Vidal Ramírez, 2000). Realizó una ardua labor al preparar los códigos civiles, penal, de enjuiciamiento civil y de enjuiciamiento penal; sin embargo, su propuesta no tuvo gran repercusión y, al final, no fue de interés de las autoridades de la época (de lo contrario, hoy estaríamos hablando del Código de Vidaurre, como solía ser en esas épocas, cuando había un autor responsable de los códigos que regularían las relaciones interpersonales con efectos jurídicos entre las partes y para la sociedad) (Vargas, 1993). Quizá la dación de estos primeros códigos, publicados de manera privada, sea el primer aporte al derecho nacional producto de una investigación jurídica.

Con la Confederación Peruano-Boliviana, en el año 1836 - que tuvo una vigencia de tres años-, se dio el primer Código Civil latinoamericano: el Código de Santa Cruz (Vidal Ramírez, 2000). Este recogió íntegramente el Código Civil francés de 1804; por ello, es casi desconocido.

Más adelante, en 1852, se creó nuestro primer Código Civil, receptor del Código Civil francés, sin ningún aporte a la investigación del derecho en esos tiempos. Fue considerado un código romanista por ser una copia casi íntegra del Código Civil de Napoleón de 1804 (Vargas, 1993). Incluso recibió, durante su larga vigencia, duras críticas, como la mencionada por nuestro historiador Jorge Basadre (1937), quien solía decir que se trataba de una mala copia. Como vemos, con el primer Código Civil peruano no hubo intento de realizar investigación jurídica, sino de incorporar el modelo que inspiró al mundo entero, sin tomar en cuenta que fue dado para una realidad muy diferente de la peruana.

Luego se elaboró nuestro Código Civil de 1936 (Vidal Ramírez, 2000), el primero con exposición de motivos; es decir, los legisladores dieron cuenta de cómo elaboraron las propuestas de las normas y su fuente de inspiración. Un gran porcentaje se tomó tal cual de teorías y normas en códigos extranjeros, como el Código Civil argentino de 1869 y el primer Código Civil brasileño, de 1916. Así, vemos cómo en nuestro segundo código se empezó la investigación jurídica - pues se estudiaron otros códigos-y se aplicó el método comparativo, herramienta muy importante. 
Por último, en el Código Civil de 1984, la exposición de motivos hace alusión a la gran influencia del derecho francés, alemán, italiano y español, en el ámbito europeo, y de los códigos argentino, brasileño y chileno, en el ámbito latinoamericano. En muchos casos, se incorporó una redacción similar a la de las normas mencionadas, con poca investigación jurídica, por lo que resultó un reflejo de la normativa europea y latinoamericana.

Con lo expuesto, se puede ver que el derecho peruano es la combinación de varias teorías y normas extranjeras que se han incorporado, en muchos casos, con una redacción taxativa y, en pocos, adecuándose a la realidad peruana. No se ha tomado en cuenta que las normas son el resultado de los problemas que aparecen en cada sociedad y que, así como las personas evolucionamos y somos diferentes, sucede lo mismo con el derecho, que no puede ser igual en todos los países. Los seres humanos que los conforman están unidos por diferentes lazos culturales, históricos, geográficos, costumbristas, educacionales, económicos, valorativos, étnicos, entre otros.

El problema que puede surgir al recibir una norma extranjera es que no se adapte al escenario donde se quiere aplicar y, por tanto, se convierta en una norma fantasma, olvidada por no encontrar armonía con el ordenamiento jurídico vigente. Esto trae como consecuencia que, en vez de solucionar, se acrecienten los problemas, pues está en conflicto con otras normas de igual categoría (Morán, 2002). Además, deja en manos de los magistrados la interpretación que deseen darle al caso concreto. Ellos muchas veces violan el principio general de equidad, que establece que cuando existe la misma razón se debe aplicar el mismo derecho. Este hecho se evidencia cuando, frente a casos iguales, cada magistrado opta por una resolución diferente. Con ello, se genera mucha incertidumbre y desconfianza en nuestro Poder Judicial, lo que trae la indiferencia y el descreimiento respecto al aparato jurisdiccional.

Frente a lo expuesto, nos hacemos la siguiente pregunta: ¿por qué se crean ciertas leyes que, en vez de aliviar los problemas, en muchos casos los multiplican? La respuesta es muy sencilla: las autoridades responsables no hacen investigación y mucho menos aplican el derecho comparado como herramienta necesaria para la elaboración de normas.

Entonces, ¿por qué no hacemos investigación? Por muchas razones. Nombraremos algunas:

a. Falta de tiempo

b. Carencia de las herramientas o materiales necesarios

c. Falta de recursos económicos

d. Desconocimiento de cómo investigar

e. Ausencia de métodos para enseñar a investigar 
f. Trabas burocráticas para hacer investigación

g. Percepción negativa de la investigación: imposición u obligación en lugar de una decisión voluntaria y real

h. Desinterés por el tema elegido

i. Carencia de beneficios económicos para el investigador

j. Falta de apoyo y respeto por la labor que desempeña el investigador

k. Falta de motivación

Sobre la base de lo expuesto, queremos dar algunos lineamientos generales para la elaboración de una tesis de derecho, los cuales sean una guía para aplicar desde el planteamiento del proyecto de investigación hasta la culminación de la tesis, a efectos de sustentarla ante el jurado calificador y obtener el grado de bachiller o el título de abogado (Ramos Núñez, 2011).

Si bien el presente artículo pretende que los graduados consigan el objetivo final y no se queden solo en el intento, consideramos que el presente aporte es el primero de cara a algunas preguntas que se nos presentan cuando pensamos en hacer investigación. Nuestro compromiso es seguir investigando a partir de las preguntas planteadas, de tal manera que podamos brindarles pautas cada vez más claras y directas para alcanzar el objetivo final: la elaboración de una tesis en derecho.

\section{LA INVESTIGACIÓN JURÍDICA}

Desde que nacemos, se evidencia nuestro instinto de conocer e investigar el mundo a nuestro alrededor, por ejemplo, con la curiosidad que tenemos frente a situaciones nuevas o al conocer personas nuevas. En cada etapa de la evolución del ser humano, se van utilizando diversos métodos para conocer e investigar lo que sucede en nuestro entorno (Mixan Mass, 2005). Conforme avanzamos, nos damos cuenta de lo poco que sabemos y comenzamos a investigar sobre lo que antes no nos habíamos percatado o aquello a lo que no le dimos la importancia que debíamos. En suma, la vida está ligada en todas sus etapas a la investigación; es decir, estamos en una constante búsqueda de la verdad y de cómo solucionar los problemas que se nos presentan en el ámbito laboral, empresarial, de gestión, familiar, educacional, amical, entre otros.

Sin embargo, cuando se nos pide hacer una investigación en derecho, consideramos que se trata de un tema desconocido, como si nunca lo hubiéramos escuchado y mucho menos practicado. Suele ocurrir que hasta nos preguntamos ¿qué es investigar?, cuando la respuesta la podemos encontrar en nosotros mismos, en nuestras experiencias cotidianas. El ser humano investiga constantemente todo fenómeno que sucede a su alrededor (Ramos Núñez, 2011). Por ejemplo, investigamos a la otra parte con la 
que celebramos un contrato para saber si cumplirá o no con las obligaciones asumidas, o si cuenta con patrimonio para garantizar el pago de la deuda. Investigamos a nuestros docentes antes de elegirlos en el proceso de matrícula, investigamos al grupo de alumnos de cada clase, a nuestro jefe, a nuestro subordinado... En fin, existe una curiosidad innata en toda persona de conocer a aquellos con los que de alguna forma nos vemos vinculados.

Para el caso que es objeto del presente artículo, debemos centrarnos en un tipo de investigación: la netamente jurídica, porque es la que nos permitirá elaborar nuestra tesis de derecho. Es decir, investigaremos un fenómeno que tiene consecuencias jurídicas y que, por lo tanto, está amparado por el ordenamiento jurídico nacional. Siendo nuestro objetivo la elaboración de una tesis de derecho, alcanzar el tan ansiado grado o el título de abogado es la meta que yace en nuestras mentes desde que ingresamos a la universidad. A ello nos dirigimos y este objetivo no solo es nuestro, sino también de nuestra familia, de la misma organización educativa y, por supuesto, de la sociedad, que espera que el profesional aplique sus conocimientos y su investigación al bienestar común y que cada aporte aplicado permita el desarrollo de nuestro derecho.

El Estado, por medio de la Sunedu y la Ley N. ${ }^{\circ} 30220$, Ley Universitaria (del 9 de julio del 2014), sentó las bases para promover la investigación en las instituciones educativas. Ellas no solo tienen la misión de brindar educación y formar futuros profesionales, sino que, además, deben asegurar una educación de calidad que se evidencie en profesionales competentes. El graduado debe estar y sentirse capacitado para asumir retos en su etapa laboral, y aportar con su quehacer al desarrollo de nuestro país. La educación es una herramienta indispensable para alcanzar el bienestar social, y la defensa y el respeto de la dignidad de la persona, quien es el fin supremo de todo Estado y sociedad actual.

Respecto a la selección del tema, todo parece ser interesante. Por eso, nos hacemos constantemente estas preguntas: ¿qué tema de trascendencia jurídica debo investigar?, ¿cómo elegir el tema jurídico que trabajaré? Es muy común que esto le suceda a quien empieza, y son cuestionamientos de mucha trascendencia como primer paso, porque de ahí parte toda investigación jurídica. Para responder de alguna forma las interrogantes planteadas, dividiremos nuestra respuesta en dos etapas de la vida universitaria que explico a continuación.

\section{Durante la etapa de formación profesional}

Es importante en esta etapa tener ya una noción de lo que significa la investigación científica y de cómo llegar al conocimiento de una investigación jurídica. Por ello, las organizaciones educativas se preocupan por preparar a los estudiantes en aquellos temas que sirven de guía para elaborar la tesis de derecho. No cabe duda del inmenso 
valor formativo que tienen, en cada uno de nosotros, los diversos cursos que se imparten para el cumplimiento de la malla curricular de cada institución. Estos producen curiosidad en sus participantes e interés para indagar más a fondo sobre determinado tema (Morales, Rincón y Tona Romero, 2005). Por ejemplo, el docente a cargo de un curso pudo tener la capacidad para inspirarnos, o tal vez no pudo culminar su enseñanza y nos dejó con algunas interrogantes. También puede suceder que el tema se asemeja a una situación personal, familiar o laboral que hemos vivido y que, por estas circunstancias, se presenta como una oportunidad para llegar a una respuesta más sólida y científica que nos permita descubrir la verdad (Morales et al., 2005).

Esta etapa resulta ser la más elemental para hacerse una idea de lo que se quiere investigar, pues se está frente a un abanico de temas entre los cuales escoger cuál es el más adecuado y, sobre todo, cuál nos causa interés y curiosidad como para investigarlo. Además, toda organización educativa cuenta con docentes especialistas, los profesores, a quienes ya se conoce y quienes nos podrían guiar para profundizar en el tema que nos causa motivación y mucha expectativa. Esta etapa podría ser mucho más eficaz si dentro del proceso de aprendizaje se llevan cursos de investigación, seminarios de tesis o cursos de metodología de la investigación; es imprescindible conocer las herramientas básicas para empezar una propia aventura en el mundo de la investigación. La pasión por investigar tendrá mucha relación con las enseñanzas impartidas por el docente investigador, pues será el primer contacto con este nuevo mundo y, por supuesto, el primer responsable de formar a los futuros investigadores.

\section{Cuando ya terminamos los estudios universitarios}

En esta etapa, seguramente con nuevos retos y nuevas obligaciones, se complica un poco la elección del tema que se quiere investigar, puesto que ya se salió del proceso de formación profesional y ahora toca que cada uno guíe su propio proceso, muchas veces sin el apoyo o ayuda tutorial que sí ofrece la universidad en la etapa de formación. Entonces se suele recordar que, efectivamente, se llevó el curso de investigación jurídica para desarrollar la tesis, pero el tema fue poco atractivo, no causó curiosidad o quizás se escuche: "El tema nunca me gustó, lo elegí solo para pasar el curso". También puede suceder que el curso nunca fue de interés del alumno y que, por ello, no prestó atención al desarrollo de cada clase. 0 puede darse el caso de que poco o nada pudo comprender de las enseñanzas del profesor que, con mucho esmero, se dedicó a impartir el curso para que sus alumnos empezaran a investigar.

Sea cual fuera la respuesta, está en manos de cada uno elegir el tema por investigar, pero ¿cómo hacerlo? Existen muchas formas; sin embargo, considero apropiado empezar este proceso partiendo de temas generales que permitan llegar al tema en particular. Es decir, aplicar el método deductivo, que suele ser una herramienta interesante y sobre 
todo eficaz para llegar a determinar de forma concreta el tema que se vaya a elegir. Veamos el siguiente ejemplo:

Alumno: Profesor, ¿cómo elijo el tema por investigar?

PROFESOR: ¿Qué área del derecho es de tu interés? ¿Qué curso estudiado te pareció más interesante?

Alumno: Me gusta, dentro de todos los cursos estudiados, el derecho civil.

Profesor: Muy bien, pero el derecho civil es muy amplio, hay más de diez cursos sobre derecho civil en la universidad que contienen el estudio doctrinario, normativo y jurisprudencial de cada libro del Código Civil.

Alumno: Me gustó, dentro del derecho civil, el curso sobre el acto jurídico.

Profesor: Bien. Sin embargo, la teoría del acto jurídico engloba muchas instituciones. ¿Algún tema fue de especial interés?

Alumno: Dentro del curso sobre el acto jurídico, me llamó mucho la atención el tema de los requisitos de validez del acto jurídico y, dentro de los requisitos de validez, me interesó el requisito de validez que establece que el objeto del acto jurídico debe ser física y jurídicamente posible.

PROFESOR: ¿Por qué le interesó el requisito de validez sobre el objeto?

Alumno: Porque, según Vidal Ramírez, en su libro El acto jurídico, se requiere la presencia de tres caracteres para que el objeto cumpla como requisito de validez: debe ser físicamente posible, jurídicamente posible y, además, determinado o determinable. A partir de eso, me gustaría saber lo siguiente: ¿cómo podría cumplir el objeto del acto jurídico con los tres caracteres si es aplicable a un bien incorporal? ¿Cómo se aplicaría, por ejemplo, para la trasferencia de una marca o una patente? ¿Será que dichos bienes no podrían ser objeto de los actos jurídicos?

PROFESOR: Con las preguntas planteadas, se hace más fácil arribar al tema que pretendes investigar.

Alumno: Me gustaría investigar la posibilidad física del objeto del acto jurídico y su implicancia en la transferencia de un bien incorporal.

En este ejemplo, se ha ido extrayendo, a partir del interés mostrado en un área del derecho, el tema que quizá sea elegido para una tesis. Para llegar a esta idea, se debe comenzar por informarse y leer, sobre todo basándose en fuentes especializadas. Seguramente se empiece repasando los apuntes de clase, pero también se puede preguntar al profesor o al asesor o especialista en metodología y elaboración de tesis. 
Lo más aconsejable es centrarse en una investigación delimitada, particular y concreta; de lo contrario, investigar temas generales tomará más tiempo y demorará la consecución del grado o título (Mixan Mass, 2002). Asimismo, delimitar el tema por investigar permite, al final de la investigación, arribar a un aporte concreto, viable y de gran trascendencia para el mundo jurídico.

Otra gran ventaja de demarcar bien el tema es la especialización en un aspecto del derecho, que es tan amplio. Frente a un mercado laboral tan competente, consideramos que la especialización se ha convertido en un instrumento valioso que ayuda al futuro abogado a mostrar su preocupación en su formación, las competencias con las que cuenta y el valor agregado que lo diferencia de los demás profesionales del derecho, sustentado en el área que investigó y que ahora conoce bien.

\section{ESTRUCTURA DE UNA TESIS DE DERECHO}

Cuando se decide elaborar una tesis, se debe entender que existe un orden, un sistema que permitirá investigar, cumpliendo paso a paso cada etapa, hasta alcanzar el objetivo final. El desorden en la investigación solo traerá frustración y, seguramente, la mala experiencia desanime de volver a intentarlo. Como se dice, no por mucho madrugar se amanece más temprano.

En primer lugar, se debe preparar el proyecto de investigación. Constará de una parte metodológica y otra teórica; es decir, se presenta lo que se pretende investigar y cómo se van a alcanzar los objetivos trazados. El proyecto es la guía que ilumina cada paso para el proceso de la investigación jurídica.

\section{Marco metodológico}

Aquí se encuentra el planteamiento del problema por investigar. Elegido el tema, sigue esta pregunta: ¿cuál es el problema? Se debe tener en cuenta que nuestra investigación en derecho tiende a ser aplicada; es decir, debe resolver una problemática vigente en la sociedad (Bardales, 2013). Para ello, se debe partir del conocimiento de la realidad y de los antecedentes del tema. Nuestra recomendación es que, al plantear las preguntas del problema, estas sean dos o más para luego elegir cuál de ellas será la que se trabaje en la investigación.

Luego de haber elegido la pregunta que interesa respecto del tema, sigue el objetivo general, el cual muestra adónde se desea llegar con el tema y los objetivos específicos, que son desmembraciones del objetivo general. Es decir, tiene que haber una correlación entre la pregunta planteada y los objetivos generales y específicos. Por ello, la sistematización, como característica primordial en la investigación, permite seguir paso a paso cada etapa y nunca saltarlas (Cañas Lastarria, 2010). 
Después de tener claros los objetivos generales y específicos, sigue la hipótesis, que en palabras sencillas no es más que una respuesta probable a la pregunta o preguntas del problema, con sus respectivas variables y sus indicadores. Se debe tener en cuenta que no se podrá elaborar una hipótesis sin antes haber elaborado la pregunta del problema y tener claro el objetivo de la investigación. Las coherencias lógicas entre estos tres elementos permitirán llevar adelante una investigación jurídica (Flores et al., 2013). Veamos un ejemplo:

- Idea por investigar: derechos reales, la multipropiedad

- Pregunta del problema: ¿cuáles serían los factores económicos y jurídicos para incorporar la multipropiedad como un nuevo derecho real dentro del ordenamiento jurídico peruano?

- Objetivo general: determinar los factores económicos y jurídicos para incorporar la multipropiedad como un nuevo derecho real dentro del ordenamiento jurídico peruano.

- Hipótesis: los factores económicos y jurídicos para incorporar a la multipropiedad como un nuevo derecho real dentro del ordenamiento jurídico peruano podrían ser, por un lado, la seguridad jurídica en su regulación, el incentivo de la inversión privada nacional e internacional, así como el desarrollo del turismo, lo que redundará en el desarrollo económico de nuestro país.

\section{Marco teórico}

En esta parte del proyecto de investigación, se acude a las diversas teorías, doctrinas, jurisprudencia nacional e internacional y al derecho comparado, con el fin de comprender cómo otros ordenamientos jurídicos han podido resolver los problemas jurídicos que enfrenta nuestro derecho nacional (Constantinesco y Da Costa, 1981). Este cúmulo de información y conocimientos tiene una doble función: por un lado, permitirá elaborar la hipótesis y, por el otro, durante el desarrollo de la tesis, servirá para comprobar la veracidad o falsedad de la hipótesis planteada inicialmente.

Se debe tener en cuenta que las hipótesis no son producto de la imaginación ni se pueden inventar, sino que tienen algún sustento teórico sólido en su componente. Para conseguirlo, tiene que apoyarse en la literatura de la especialidad, en los casos jurisprudenciales, en las experiencias vividas y, por supuesto, en muchas ocasiones, en el derecho comparado. 


\section{LINEAMIENTOS GENERALES PARA ELABORAR LA TESIS DE DERECHO}

Antes del proyecto, se debe tener clara la idea por investigar, puesto que, si el tema elegido no interesa, seguramente no se avanzará con la investigación, se hará tedioso desarrollarla y seguramente se dejará con el riesgo de tener que empezar otra desde cero (Hernández, Fernández y Baptista, 2006). Es importante que el tema elegido salga de quien lo investigará, sin imposiciones, y le apasione, de modo que no lo abandone.

a. El proyecto de investigación debe ser aprobado por la organización educativa, que deberá revisar si este es viable, si constituye un tema interesante y si parte de la problemática del momento para llevar el fenómeno jurídico a posibles soluciones, con miras a hacer un aporte al derecho nacional (Flor, 2016).

b. Es preferible que el asesor de tesis sea de la especialidad del tema por investigar o especialista en metodología de la investigación. Sería una ventaja que el asesor comparta ambas especialidades.

c. La elaboración de la tesis de derecho debe tener como guía el marco metodológico descrito en el proyecto. Hay que recordar que la finalidad es probar la veracidad o falsedad de la hipótesis planteada.

d. El marco teórico debe elaborarse mediante la recolección de datos e información relevante y la consulta de literatura especializada (doctrina, teorías generales y especializadas, jurisprudencia nacional e internacional, y normativa interna e internacional). Esto permite comprobar o negar la hipótesis planteada y permite visualizar cuáles pueden ser las sugerencias que redunden en un aporte al derecho nacional.

e. El diseño de la investigación, la selección de la muestra (Hernández et al., 2006) y la aplicación de diversas técnicas de investigación (como las entrevistas, los focus group, las mesas redondas, las charlas, las conferencias, las reuniones de trabajo y de investigación, entre otros) ayudarán a la comprobación de la hipótesis planteada.

f. Se debe analizar cada documento con total objetividad, relacionando, en primer lugar, la normativa, la doctrina y la jurisprudencia. Este trinomio permitirá un enfoque más amplio del tema y arribar a conclusiones objetivas y prácticas (Hernández-Sampieri y Torres, 2018).

g. El aporte del investigador al derecho nacional puede darse mediante propuestas claras y precisas, que pueden consistir en la modificación de una norma, la dación de otra que conduzca a la solución del problema, una mejor interpretación de la norma o la precisión de criterios uniformes de interpretación normativa. Todo ello debe sustentarse con base científica y haber sido analizado de modo objetivo para asegurar una fidelidad total en la investigación (Flor, 2016). 


\section{NORMATIVA SOBRE LA INVESTIGACIÓN JURÍDICA}

Haciendo una búsqueda de las normas del Estado peruano que regulen la investigación científica en general, y la jurídica en específico, no encontramos ninguna sobre los métodos de investigación, los lineamientos generales, los componentes y las etapas que corresponden al proceso de investigación. Lo que conocemos ahora se ha extraído de las experiencias de grandes investigadores que, en su actuar, sea individual o colectivo, han logrado los objetivos indicados en sus trabajos de investigación y, con ello, han transformado diversas ciencias (entre ellas, el derecho).

Sin embargo, existe interés en promover la investigación en todas las áreas científicas, es una política pública de nuestro país. La Ley N. ${ }^{\circ}$ 30220, Ley Universitaria, señala que es un fin de la universidad realizar y promover, entre otras cosas, la investigación científica, tecnológica y humanística (la creación intelectual y artística). Asimismo, indica que una función de la universidad es la investigación y establece ciertos requisitos para la obtención de los grados y títulos universitarios. En todos ellos, menciona la aprobación de un trabajo de investigación para obtener el grado de bachiller y la aprobación de una tesis para la obtención del título profesional, el grado de maestro y el grado de doctor. Resaltamos el artículo 48 de la ley en mención:

La investigación constituye una función esencial y obligatoria de la universidad, que la fomenta y realiza respondiendo, a través de la producción de conocimiento y desarrollo de tecnologías, a las necesidades de la sociedad, con especial énfasis en la realidad nacional. Los docentes, estudiantes y graduados participan en la actividad investigadora en su propia institución o en redes de investigación nacional o internacional, creadas por las instituciones universitarias públicas o privadas. (Ley N. $\left.{ }^{\circ} 30220,2014\right)$

\section{CONCLUSIONES SOBRE EL APORTE DEL INVESTIGADOR AL DESARROLLO DEL DERECHO NACIONAL EN TIEMPOS ACTUALES}

La investigación, como se ha venido indicando, se ha convertido en un instrumento necesario para descubrir la respuesta a tantas interrogantes que nos hacemos a lo largo de nuestras vidas. Hoy más que nunca, en el estado de emergencia que vivimos para luchar contra la pandemia que afecta a toda la humanidad, nos informarnos por los medios de comunicación que se viene investigando la vacuna que nos prevendrá de contraer el virus, o que se investiga el anticuerpo que permitirá atacarlo dentro de nuestro propio cuerpo, o que se investiga para crear respiradores mecánicos para pacientes en estado crítico... Y, así, hoy la palabra investigar está en la mente de todos. Nos damos cuenta recién de que en las manos de los investigadores se encuentra el destino de nuestras vidas y el futuro de la humanidad. No cabe duda del valor que viene ganando la investigación y, por supuesto, el respeto y la admiración al papel que desempeñan los investigadores (Zorrilla, 2011). 
Probablemente, el presente que vivimos y el COVID-19 cambiarán nuestra percepción sobre la trascendencia de la investigación, y esperemos que nuestros gobernantes tomen conciencia y se den cuenta de que, hoy más que nunca, debemos invertir en ella, y no solo esperar los resultados provenientes de otros países. El tiempo no espera por nadie, tomemos la decisión y tengamos la confianza de que somos capaces, de que podemos si queremos, porque sabemos que existen buenos científicos peruanos en diversas áreas del conocimiento, con las cualidades necesarias, pero sobre todo con la objetividad y la ética, para arribar a las respuestas que todos buscamos.

En el campo del derecho, nos enfrentamos a nuevas interrogantes producto de los efectos que viene ocasionando la pandemia en las relaciones jurídicas. Nos preguntamos: ¿cómo se resolverán estos nuevos conflictos que hoy afectan a la sociedad? Queda claro que, para encontrar esta y otras respuestas a las muchas preguntas que nos hacemos, debemos investigar. Es el camino para alcanzar la verdad en beneficio del desarrollo de nuestro país. Si no hay investigación, no hay avance del derecho y seguiremos siendo meros destinatarios de las teorías y corrientes doctrinarias. Asumiremos la posición de espectadores de los avances que se han venido produciendo en las teorías tradicionales europeas, a diferencia de aquellas investigaciones dirigidas por investigadores interesados en el avance de las ciencias jurídicas (Zorrilla, 2011).

Por ejemplo, pensemos en los alemanes, quienes no se quedaron con el aporte del derecho francés, sino que hurgaron las bases romanísticas y avanzaron para brindar al derecho las teorías modernas, muchas seguidas por otros ordenamientos jurídicos, como el nuestro. Lo mismo ocurrió con los italianos, que realizaron un análisis partiendo de las teorías más importantes y trascendentales, como la francesa y la alemana, para seguir brindando aportes (Morán, 2002). No se quedaron como espectadores pasivos del conocimiento, sino que siguieron investigando con el fin de adaptar tales teorías a su realidad.

Esto no sucede con el derecho peruano, que, hasta la fecha, viene incorporando diversas teorías y normas extranjeras, muchas veces con la justificación de estar a la par con el avance en el derecho. Hemos aplicado estas leyes sin antes realizar un estudio pormenorizado de cuáles serían los impactos en la sociedad peruana, lo que ha traído como consecuencia diversas interpretaciones de los magistrados, colisión entre normas de un mismo rango, conflictos al momento de aplicar el derecho. Esto nos ha llevado a resolver casos iguales con normas diferentes (Morán, 2002).

Hoy la investigación es una política pública del Estado. Por ello, para alcanzar el grado de bachiller, debemos realizar un trabajo de investigación. Este es un gran cambio, pues ya no existe más el bachillerato automático, que saltaba ese primer contacto con la investigación y traía como consecuencia que muy pocos eligieran graduarse con una tesis para obtener el título de abogado. Preferían la sustentación de expedientes que, a la 
larga, sin darnos cuenta, abarcan más temas y es muchas veces más difícil de preparar (López Escarcena, 2011).

Como sabemos, en una tesis se establecen límites para el investigador y también para el jurado calificador (López Escarcena, 2011). Además, motiva la especialización en el tema y la defensa de los resultados obtenidos en la investigación, pues suponen el cambio que se quiere aportar a la sociedad, lo que redunda definitivamente en el desarrollo del derecho.

Conocemos que, en países desarrollados, un gran porcentaje de su presupuesto se destina a la investigación; en cambio, muy a nuestro pesar, en el Perú no se está dando a la investigación la importancia que le corresponde (Hernández-Sampieri y Torres, 2018). Por ello, consideramos que ya es hora de dejar de ser simples receptores de teorías y leyes extranjeras. Es tiempo de convertirnos en promotores de normas que permitan resolver problemas sociales vigentes y que hagan posible la paz social para el bienestar de todos.

Investigar es parte de nuestra naturaleza, nosotros somos investigadores natos. No la dejemos de lado pensando que nos enfrentamos a un fenómeno inalcanzable; al contrario, es nuestra aliada y, en muchos casos, como el momento en que vivimos, es nuestra salvación. Nos acompañará en cada etapa de nuestra existencia para el bienestar de la humanidad.

\section{REFERENCIAS}

Bardales, M. J. S. (2013). El método en la investigación jurídica. Derecho y Cambio Social, 10(32), 33.

Basadre, J. (1937). Historia del derecho peruano (vol. 1). Lima: Editorial Antena.

Basadre, J. (1984). Historia del derecho peruano. Lima: Ediciones Gráficas.

Cañas Lastarria, R. (2010). Esquema tipo de un método de investigación dogmática en derecho positivo. Revista de Derecho de la Pontificia Universidad Católica de Valparaíso, (2). doi: 10.4151/ISSN.07186851-Vol.0-Num.2-Fulltext.30.

Constantinesco, L. J., y Da Costa, E. F. (1981). Tratado de derecho comparado. Introducción al derecho comparado. Madrid: Tecnos.

Flor, L. M. R. (2016). Metodología de investigación jurídica (vol. 8). Cuenca: Ediciones de la Universidad de Castilla-La Mancha.

Flores, M. D., Franco, M. E. V. E., Ricalde, D. C., Garduño, A. A. L., y Apáez, M. R. (2013). Metodología de la investigación. Ciudad de México: Editorial Trillas. 
Hernández, R., Fernández, C., y Baptista, P. (2006). Metodología de la investigación. Ciudad de México: McGraw Hill.

Hernández-Sampieri, R., y Torres, C. P. M. (2018). Metodología de la investigación (vol. 4). Ciudad de México: McGraw-Hill Interamericana.

Ley N. ${ }^{\circ} 30220$, Nueva Ley Universitaria. (9 de julio del 2014). Recuperado del sitio web del Congreso de la República: http://www2.congreso.gob.pe/Sicr/TraDocEstProc/ Expvirt_2011.nsf/Repexpvirt?OpenForm\&Db=201100154\&View

López Escarcena, S. (2011). Para escribir una tesis jurídica: técnicas de investigación en derecho. lus et Praxis, 17(1), 231-246.

Mixan Mass, F. (2002). Lógica enunciativa jurídica. Trujillo: Ediciones BLG.

Mixan Mass, F. (2005). Cuestiones epistemológicas y teoría de la investigación y de la prueba. Trujillo: Ediciones BGL.

Morales, O. A., Rincón, Á. G., y Tona Romero, J. (2005). Cómo enseñar a investigar en la universidad. Educere, 9(29), 217-225.

Morán, G. M. (2002). El derecho comparado como disciplina jurídica: la importancia de la investigación y la docencia del derecho comparado y la utilidad del método comparado en el ámbito jurídico. Anuario da Facultade de Dereito da Universidade da Coruña, (6), 501-529.

Ramos Núñez, C. (2011). Cómo hacer una tesis de derecho y no envejecer en el intento. Lima: Editora Jurídica Grijley.

Vargas, J. (1993). Historia del derecho peruano: parte general y derecho incaico. Universidad de Lima, Fondo Editorial.

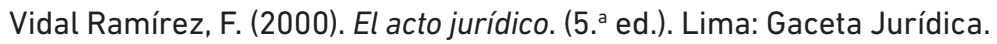

Zorrilla, M. S. (2011). La metodología en la investigación jurídica: características peculiares y pautas generales para investigar en el derecho. Revista Telemática de Filosofía del Derecho, (14), 317-358. 